\title{
Introduction: the relevance of studying fertility across time and space
}

\author{
Tomáš Sobotka ${ }^{1, *}$
}

\section{The contemporary global variation in fertility}

Research on aggregate-level trends, patterns and determinants of fertility has always been at the top of demographers' agendas. Ultimately, questions about fertility and reproduction touch upon the fundamental issue of the replacement and survival of our species (Coleman 1998). Current "ultra-low" fertility rates in many countries in Europe and East Asia give rise to concerns about the potential demographic implosion and its consequences (e.g., Funabashi 2018). At the same time, some countries in Sub-Saharan Africa continue to have very high fertility rates (see Shapiro and Hinde in this volume) that fuel long-term demographic momentum. As Potts et al. (2011) observed about the situation in Niger, this trend "casts a threatening shadow" over the future of these countries, and over the sustainability of their populations. Although global fertility has been converging to relatively low levels across most countries and regions (Strulik and Vollmer 2013), the gap between the highest-fertility country, Niger, with an estimated total fertility rate (TFR) of 6.95 in 2015-2020 (UN 2019), and South Korea, with a TFR of 0.92 in 2019, remains huge.

In between these two extremes and the two contrasting concerns about very low and very high fertility, the study of macro-level fertility remains key for understanding past population trends and for projecting future population. Two factors, the pace of the fertility decline in Sub-Saharan Africa and the depth of the fertility decline in low-fertility countries, will determine future global population growth, and its eventual stabilisation or reversal (Lutz et al. 2018; Vollset et al. 2020). Many big questions regarding fertility trends and determinants have not yet been sufficiently answered or studied. As countries complete the (first) fertility transition, is fertility likely to fall to very low levels in most societies? If it does, is it likely to recover later, or to remain stuck at very low, "suboptimal" levels for many decades,

\footnotetext{
${ }^{1}$ Vienna Institute of Demography (VID), Austrian Academy of Sciences, Wittgenstein Centre for Demography and Global Human Capital (IIASA, OeAW, University of Vienna), Vienna, Austria

*Correspondence to: Tomáš Sobotka, tomas.sobotka@oeaw.ac.at
} 
thus locking countries in a low fertility trap (Lutz et al. 2006), and heralding a shift towards low family size ideals and preferences? Recent experiences of economic shocks and the uncertainty resulting from the COVID-19 pandemic make such a shift more likely, and add another layer of uncertainty about the future direction of fertility change.

In addition to being unable to answer these questions, our insufficient understanding of contemporary changes in fertility and reproduction is underscored by the ongoing lively discussions on the factors driving fertility change, variation and reversals in post-transitional societies. The pronounced fertility declines recorded since 2008 in many of the countries that already had low fertility took many demographers by surprise, and stimulated reflections about the changes in fertility preferences, the new meaning of parenthood and reproduction, and the changes in partnership formation patterns among young adults (see Sections 3 and 4 below).

This issue of the Vienna Yearbook of Population Research brings together many perspectives on the past, present and future of fertility. It features a selection of articles that were presented at the 2018 Wittgenstein Centre Conference and the Third Human Fertility Database Symposium on "Fertility across Time and Space", and invited contributions that discuss the key drivers of future fertility. This volume covers both countries with very high fertility (article by Shapiro and Hinde) and countries with "ultra-low fertility", especially in East Asia (contributions by Cheng and Fukuda). It features studies on historical fertility declines (Poulain et al. on marital fertility in Sardinia), as well as articles dealing with recent trends (e.g., the study by Cheng) and presenting fertility projections (article by Potančoková and Marois). While many of the articles are empirically oriented, some have a strong methodological (contribution by Mogi and del Mundo) or theoretical focus (articles by Cavalli and by Poulain et al.). Most of the contributions focus on fertility levels, but several shed light on changes in fertility timing (studies by Kazenin and Kozlov, and by Mogi and del Mundo). The articles also provide diverse geographical coverage, ranging from a global perspective (study by Cavalli), to a focus on broader regions or groups of countries (articles by Potančoková and Marois; Mogi and del Mundo; Shapiro and Hinde; and by Cheng), to one-country studies (article by Kazenin and Kozlov), to in-depth research focusing on historical fertility change in two villages in Sardinia (research by Poulain et al.).

To discuss and position each contribution within contemporary fertility research, I outline some of the key research themes and questions on aggregate-level fertility they address, and discuss the emerging features of post-transitional fertility (Section 2). Then, I review the arguments and conclusions in the Demographic Debate regarding the main factors that are likely to affect fertility in the future (Section 3). Finally, I speculate about the emerging features of a new fertility landscape characterised by new uncertainties, lower reproductive preferences and depressed fertility. 


\section{Key questions in contemporary macro-level fertility research}

Fertility rates in many parts of the world are continuing to change rapidly, and often in initially unexpected directions (e.g., Hellstrand et al. 2020a and Rotkirch this volume). In addition, period fertility rates are frequently affected by changes in the timing of union formation and childbearing, contributing to their instability. The studies in this volume can help us analyse and understand the diversity of contemporary fertility change. To review these studies in more detail, I outline selected key questions in contemporary fertility research that they address.

\subsection{What drives the fertility shift from high to relatively low fertility levels?}

This is the core question pertaining to the fertility transition and its mechanisms, and, in a broader perspective, to the (first) demographic transition. To date, there is considerable disagreement about the extent to which the fertility transition is driven by structural and socio-economic forces, or by technological and ideational changes (Bryant 2007). Michel Poulain, Dany Chambre, Pino Ledda, and Anne Herm address the main premise of the demographic transition theory: i.e., that a decrease in infant and child mortality precedes the onset of fertility decline, and that mortality decline is an important driving force of fertility change. Poulain et al. provide an indepth investigation of marital fertility transitions in two villages in Sardinia. Their study, covering a period from the late $19^{\text {th }}$ century to the present time, concludes that the close association between the decreases in mortality and fertility indicates that the decline in stillbirths and infant mortality in the studied populations "might have been at least partly responsible for the corresponding decrease in fertility" (p. 231). At the level of individual families, the "number of surviving children, rather than a specific number of births, serves as an important predictor of the likelihood of having another child" (p. 232). However, the causal link between mortality and fertility appears to run in both directions: longer birth intervals and a lower number of children born - two manifestations of the progressing fertility transition are also found to be associated with better chances of children surviving, and, thus, with lower early mortality. In addition, broader socio-economic and cultural developments - including improvements in health care, well-being, transport links and education - are shown to be associated with both declining mortality and family size limitation.

The contemporary debate on the fertility transition often focuses on higherfertility countries, especially in Sub-Saharan Africa, and the drivers of fertility change in the region. Two important contributions, by Bongaarts and Casterline (2013) and by Bongaarts (2017), examine the unique features of the African fertility transition. They document that fertility decline in Sub-Saharan Africa, once initiated, has been slower than in other world regions (see also Shapiro 
and Hinde 2017), and that the ideal family size remains higher there than it is elsewhere. In addition, women in many parts of the continent have poor access to modern contraception and high rates of unmet need for contraceptive use. While the correlations between the main indicators of socio-economic development (GDP per capita, education, life expectancy and urbanisation) and fertility in the region have the expected negative sign, Bongaarts (2017: 55) highlights what he calls the Africa effect: at "a given level of development, Africa's fertility is higher, contraceptive use is lower, and desired family size is higher" than in the less developed countries outside the continent. Many societies in Sub-Saharan Africa are characterised by a strong pro-natalist culture that sustains higher family size preferences.

David Shapiro and Andrew Hinde contribute to the debate on the factors driving the fertility transition in the region. They examine fertility change and broader socioeconomic and demographic factors affecting fertility in seven countries of SubSaharan Africa that have the highest fertility rates globally, and are the "laggards" in the global fertility transition: Chad, the Democratic Republic of Congo (DRC), Equatorial Guinea, The Gambia, Mali, Niger and Somalia. While all of these countries have experienced the onset of fertility decline, their fertility levels have declined slowly. Indeed, by 2010-2015, five of these countries had not even met the criterion of a 10 per cent decline from the peak level that is often used as a benchmark for fertility transition. Shapiro and Hinde document that the analysed countries are experiencing a combination of social, economic and cultural factors that are sustaining their higher fertility levels and slowing their fertility declines. In comparison with other countries in the region, they display much lower levels of modern contraception use - especially among women in a union - earlier marriage, higher ideal family sizes (reaching a staggering 9.2 children per woman in Niger; see Table 2 in Shapiro and Hinde, this volume), fewer years of schooling and higher shares of the population with no education (except in the DRC); and, in most countries, lower GDP per capita and higher infant and child mortality. All of the analysed countries except the DRC have a high proportion of Muslims in the population, ranging from $65 \%$ in Chad to $100 \%$ in Somalia, and thus reflect the stronger preference for children among Muslim women. Taken together, these factors form a "multi-dimensional space" associated with "fertility promoting values" as well as "resistance to fertility decline". The current high fertility rates in these countries build up momentum for continued rapid population growth in the coming decades, posing challenges to improvements in well-being, and contributing substantially to future population growth in Sub-Saharan Africa.

Future fertility trends in the "laggard countries" and in the region as a whole will also be affected by violence and governance failures. Alicia Adsera's debate contribution brings up the "lack of leadership" as one of the key forces hampering broader socio-economic development, and thus slowing down the pace of fertility decline. It is no coincidence that a number of the countries analysed by Hinde and Shapiro are experiencing violent ethnic and religious conflicts (Chad, DRC, Mali, Niger, Somalia), and their governments do not have full control over the whole territory. Most of these countries have dysfunctional and weak governments that are 
not able to deliver even basic infrastructure, education, health care and security to their populations. In the countries that are managing to expand education, especially for girls, Wolfgang Lutz (this volume) highlights the dual effect of education on lowering fertility: it "reduces the ideal family size, presumably through changes in values and in the associated quantity/quality considerations; and it empowers women to actually realize this smaller family size by averting unwanted births" (p. 64).

\subsection{Which factors sustain the fertility transition, and which factors contribute to fertility stalls and reversals?}

Once the fertility transition is under way, is it likely to proceed without interruptions until fertility reaches low levels? Or does fertility decline often follow a less straightforward trajectory marked by stalls and reversals? Which factors sustain the transition to low fertility? Studies published since the early $21^{\text {st }}$ century have examined the rising number of countries in Africa, Asia and Latin America where the shift towards lower fertility has at least temporarily stalled, and have discussed the factors contributing to these stalled transitions. Looking at seven countries across these three continents, Bongaarts (2006) concluded that these stalls in the fertility transition were linked to stagnating contraceptive use, and to a stabilisation in the demand for contraception and in the number of wanted births, with no evidence of rising unwanted or unplanned births. A number of studies have focused on the evidence of stagnation in the fertility transition in Africa in the 1990s and early 2000s. Bongaarts (2003) and Shapiro and Gebreselassie (2008) highlighted the role of educational improvements in the course of the fertility transition, observing that less educated women tend to have both a higher (although declining) desired family size and higher levels of unwanted fertility. They suggested that low or stagnating levels of schooling can cause the fertility transition to stall. In line with these expectations, Goujon et al. (2015) and Kebede et al. (2019) linked the stalling of the fertility transition in some countries of Sub-Saharan Africa to the setbacks in education in the 1980s and 1990s, when the share of women without formal education stagnated or declined only slightly in Kenya, Nigeria, Côte d'Ivoire and some other countries. At the same time, fertility rates among women with no education remained high or even increased, fuelling the overall stagnation or slowdown of the decline in period fertility.

The current evidence suggests that the experience of fertility stalls or reversals is relatively common in the countries undergoing the fertility transition, with some societies experiencing a prolonged period of stalling fertility at higher levels lasting two or more decades. Al Zalak and Goujon's (2017) analysis of increasing fertility in Egypt between 2005 and 2015 also showed that changes in the timing of marriage and childbearing could explain some of the fertility stalls. During that period, more women married at an early age (before age 25), and the previous gradual shift towards later marriage and childbearing had come to an end. 
Although the fertility transition and the increase in educational attainment often lead to a shift towards later marriage and parenthood (Bongaarts et al. 2017), this trend is often uneven, and is far from universal among the transitional societies. Three of the Central Asian countries that were formerly part of the Soviet Union Kazakhstan, Kyrgyzstan and Turkmenistan - experienced an upturn in their period fertility rates, and a shift towards earlier childbearing or a stabilisation in their patterns of early births in the 2000s and 2010s (Spoorenberg 2015). The study by Vladimir Kazenin and Konstantin Kozlov puts a spotlight on the absence of first birth postponement in Kyrgyzstan. The authors look at the socio-economic and cultural factors that have been sustaining the pattern of early union formation and childbearing in these countries. Their research underscores the role of the "expected" factors (especially lower education and rural residence), but also the importance of cultural and technological factors, such as access to information (limited access to the internet); acceptance of domestic violence as a measure of women's lack of power; and ethnicity, which is closely linked to religiosity and "traditionalism" in family relations. Women from the Uzbek ethnic minority, who have the lowest levels of educational attainment and internet access and the highest levels of acceptance of domestic violence among the three groups analysed, also display a pattern of early union formation and of a faster transition to the first birth after union formation. This analysis underscores that culture, religion and women's autonomy continue to affect fertility change and variation.

\subsection{Emerging patterns of post-transitional fertility: stable preferences combined with low, delayed and unstable fertility rates}

In the last three decades, many countries in Asia and Latin America - including Bangladesh, Brazil, China, Colombia, Iran, Malaysia, Turkey and Viet Nam - experienced a decline in their period TFR to sub-replacement levels, thus marking the completion of their fertility transition. A locus of low fertility has been increasingly moving towards middle-income countries. As ever more countries are set to join the "low-fertility club" in the near future, it is worth looking at the experiences of the countries that completed their fertility transition in the 1960s-1990s.

What are the key emerging features of post-transitional fertility? Arguably, the most important finding is the absence of a stabilisation of fertility around the replacement level. As Wolfgang Lutz (this volume) puts it, "we are groping in the dark and only feel confident in saying that the long-held view that all countries will ultimately converge to the so-called replacement level of 2.1 is untenable and without scientific basis" (p. 65). In most countries, period fertility continues to decline once this threshold has been hit. Over the last decade, all post-transitional countries with relatively higher fertility have experienced a decline in their period TFR, with most of them seeing their TFR drop from around 1.9-2.1 to around 1.7 (Figure 1). However, some of these countries saw a sharper fall in fertility: in 2019, the TFR plunged to 1.53 in Norway, and to a record low of 1.35 in Finland (Rotkirch, this volume). 
Figure 1:

Total fertility rate (TFR) in 2008 and 2019 in highly developed countries with a higher TFR in 2008 (except Israel); data ranked from the highest value in 2008

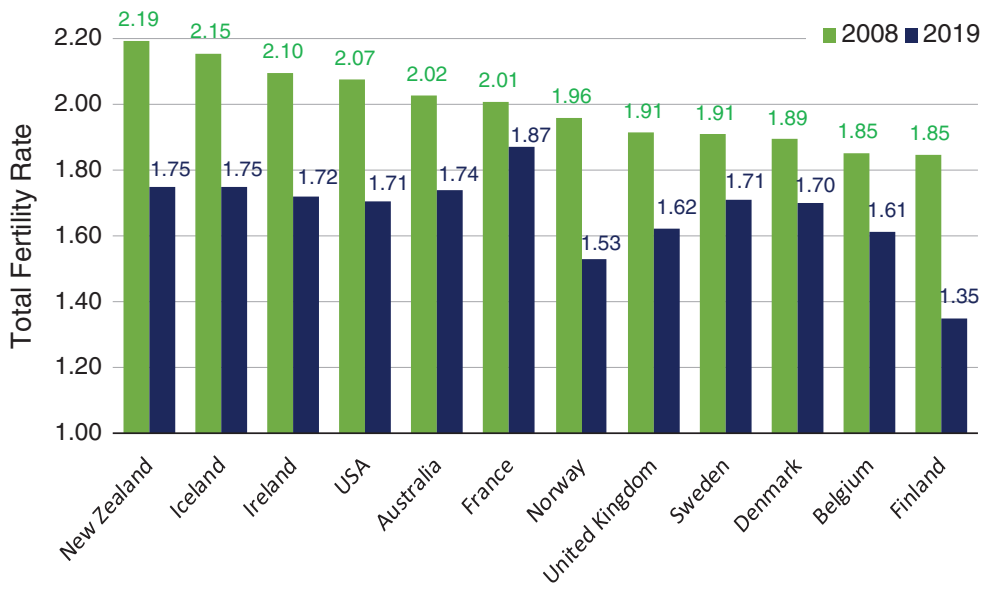

Source: National statistical offices (October 2020).

Note: Recent data for Belgium and Australia refer to 2018; data for some countries are preliminary and may be revised.

These sharp declines are most unexpected in the Nordic countries, which are often seen as forerunners in implementing work-life balance policies (Lappegård this volume; Lutz this volume) that enabled them to achieve a "virtuous combination" of high levels of women's employment, high gender equality and relatively high fertility. While the recent fertility declines have been driven in part by a renewed trend towards delayed family formation, the spread, the magnitude and the duration of these fertility downturns indicate that they are likely to be more entrenched, and to lead to declines in cohort fertility as well (Hellstrand et al. 2020b for the Nordic countries).

With the possible exception of China (Basten and Gu 2013), the very low fertility observed in many post-transitional countries today does not reflect the reproductive intentions, desires and ideals of individual men and women. In Europe, the United States, Japan, Canada and other low-fertility countries, the indicators of family size preferences typically reach around or slightly above two births on average, and have remained relatively stable over time (Sobotka and Beaujouan 2014; Beaujouan and Berghammer 2019; Edmonston et al. 2010; Fukuda and Saotome 2018; see also Esteve et al. this volume). Among younger women across educational groups, including women with a university degree, the intended or desired family size is generally around two children (Beaujouan and Berghammer 2019; Berrington and Pattaro 2014). In addition, the share of younger respondents who express an ideal or an intention to be permanently childless remains low in most countries 
(e.g., Rybińska (2020) for the United States; Esteve et al. this volume). This evidence suggests that one of the key explanations for low fertility rates is the inability of women and men to realise their fertility plans, with the intentionsbehaviour gap typically being larger in countries with very low fertility (e.g., in Italy, Greece and Spain) and among women with higher education (Beaujouan and Berghammer 2019). Albert Esteve et al. (this volume) argue that the gap is built over the life course, and is partly explained by less frequent and later partnership formation (see also Section 3 below).

In many countries, post-transitional fertility has been unstable, characterised by distinct waves of fertility declines and upturns over time (Sobotka 2017). These ups and downs of "rollercoaster fertility" are largely driven by changes in the timing of parenthood in response to economic shocks, changes in family policies and other factors; and do not affect the completed fertility rate, which generally follows a much more stable trend. As a result, period TFRs often send the wrong signal about the direction and the pace of fertility change, as well as about the differences in fertility levels between countries and populations (Sobotka and Lutz 2011). This fallacy of overinterpreting short-term period fertility shifts is also found in some contributions studying the changing links between selected determinants of fertility and fertility rates (e.g., Myrskylä et al. 2009).

Another key feature of post-transitional fertility is a shift towards entering parenthood at later reproductive ages that has been progressing in many countries without interruption since the 1970s (Sobotka and Beaujouan 2018). Anna Rotkirch (this volume) highlights the complex nature of fertility decisions today, which involve a much higher degree of ambivalence about when "it is safe and desirable to have children" and a longer list of "preconditions" for parenthood that have to be fulfilled before men and women are ready to have a child. Among these preconditions, finding the right partner and being able to live independently score especially high. Esteve et al. (this volume) argue that the timing of partnership formation is one of the key determinants of contemporary fertility differences. This link is most apparent in East Asian countries, where marriage remains a precondition for parenthood (Fukuda this volume). The rapid expansion of tertiary education, especially among women, and the increasing involvement of women in the labour force, have contributed to a sharp rise in the mean age at first marriage across the region (Cheng this volume, Fukuda this volume).

The ever-later timing of entry into parenthood, in combination with a rise in lifetime childlessness, indicate that women and men are spending increasing shares of their reproductive lives without children. For instance, in Japan and Spain, close to $40 \%$ of women currently remain childless at age 35 (Human Fertility Database 2020), a threshold at which infertility starts to increase (Leridon 2008). To account for both the changes in childlessness and the shift towards later parenthood, Ryohei Mogi and Michael Dominic del Mundo propose a new index of the average length of life women spend without children during their reproductive period (15-49): the Expected Years Without Children (EYWC). Focusing on women in eight countries born in the 1940s to the early 1960s, they show that first birth postponement was 
the main driver behind the rise in the EYWC in Canada, the Netherlands, Norway, Sweden and the United States.

The increase in childbearing after age 35 has been fastest among childless women and women with one child. This implies that these women are at higher risk of being unable to realise their fertility plans due to infertility (e.g., Beaujouan et al. 2019). As Esteve et al. (this volume) highlight, fertility decisions are increasingly constrained by the ages of the prospective parents. Postponed parenthood is also linked to a rising reliance on assisted reproductive technology (ART), which is becoming an important means for achieving pregnancy among many women and couples past age 35. For instance, in Japan, the share of children born to women who had ART treatment jumped from $1.0 \%$ in 2000 to $2.7 \%$ in 2010, and to $6.0 \%$ in 2017 (own computations based on Ishihara et al. 2019). In Spain, 8.6\% of all births in 2018 were to women who underwent ART treatment (computations based on Table 3.17 in Registro SEF 2018).

\subsection{How low can fertility fall in post-transitional countries? What explains the decline in fertility to ultra-low levels?}

Within the current variation in post-transitional fertility trends, demographers are especially concerned about the countries and regions with "ultra-low" or "lowestlow" fertility rates. The question of "how low can fertility fall" is both fascinating and relevant from the standpoint of governments, societies and policy-makers dealing with the likely long-term consequences of depopulation and population ageing. While some studies have tried to empirically determine the lower bound of period and cohort fertility (Golini 1998), a more plausible view suggests that there is no obvious limit to low fertility. At least from a period perspective, zero is the ultimate limit once reproduction is culturally determined (Lutz this volume). Equally important, also from the perspective of population projections, is the question of how long extreme low fertility is likely to last: Is it a transient phenomenon, merely driven by a temporary shift towards later parenthood, or is it likely to become a permanent feature of many societies? Lutz et al.'s (2006) low fertility trap hypothesis argues that in societies with a long-standing experience of very low fertility, the family size ideals of younger generations socialised in small families and in an environment with few children around could change, leading to a spiral of declining numbers of births, low family size ideals and very low fertility.

Currently, two broader regions, Eastern Asia and Southern Europe, are the "hotspots" of global low fertility, with the Republic of Korea (South Korea) achieving new lows in its period TFR almost every year: the TFR in the country dropped to 0.92 in 2019, and reached the even lower level of 0.72 in the capital city of Seoul (KOSIS 2020). ${ }^{1}$ What are the characteristics of countries with very

1 Based on trends in the absolute number of births in January-August 2020, which were down 9.5\% compared to the same period in 2019, the TFR in South Korea is likely to drop below 0.85 in 2020 . 
low fertility? Table 1 summarises the selected features of period and cohort fertility in seven countries and territories in Southern Europe and East Asia: Greece, Italy, Spain, Hong Kong, Japan, South Korea and Taiwan. In each of these countries, the tempo-adjusted indicator of period fertility in 2016 and the completed fertility of women born in 1978 were above the recent conventional period TFR levels, signalling that the "ultra-low" fertility levels are partly fuelled by the ongoing postponement of parenthood. At the same time, the tempo-adjusted period fertility rates and the completed fertility rates in these countries generally reached levels of around 1.4-1.5. Thus, regardless of which indicator is used, fertility in these countries is low, with the completed fertility rate reaching the lowest level globally in Hong Kong (1.25), followed by Spain (1.36). The low mean family size in these societies is due to a combination of a high share of women remaining childless (reaching 28\% in Japan and 30\% in Hong Kong) and a high share of women having only one child (see also Zeman et al. 2018). Southern European and East Asian societies are also characterised by a pattern of late parenthood, with the mean age at first birth among women surpassing 30 years, and reaching close to 32 years in South Korea.

What are the key factors contributing to "ultra-low fertility"? Alice Cheng (this volume) provides a review of the institutional factors that underlie very low fertility in East Asia, with a particular focus on Japan, Hong Kong, South Korea and Taiwan, but also incorporating data and literature on China (see also Raymo et al. 2015). Cheng highlights the historical and cultural roots of ultra-low fertility in the region, with traditional Confucian ideology placing a strong emphasis on formal academic attainment. Moreover, Confucianism promoted a patriarchal view of male and elder dominance, and stressed women's responsibilities to provide care as part of their roles as wives, mothers, and daughters. Female empowerment in education and employment, together with long work hours and rigid labour market structures (Brinton and Oh 2019), clash with these traditional norms and expectations: the "patriarchal cultural and family systems of East Asia are maladapted to women's rising status and economic independence" (Cheng, this volume: 84).

An important feature of East Asian cultures is their low acceptance of unmarried cohabitation, of non-traditional family forms and, even more so, of childbearing outside marriage (Fukuda this volume; Cheng this volume; Raymo et al. 2015). The prevailing gender inequalities, the rising economic uncertainty, the high direct and opportunity costs of childbearing - especially for women - and the notion that marriage and childbearing are "too stressful" and involve "too much personal sacrifice" (Cheng this volume), have led to both the erosion and the postponement of marriage. Cheng argues that "the social mentality and the prevailing norms about marriage and childbearing are incompatible with the rising agency of women" (p. 110). Stuart Gietel-Basten (this volume: 40) refers to the "cultural and institutional grip that older generations have on the young", which sustains gender inequality. As childbearing is exclusively linked to marriage, less frequent marriage, later marriage and the rising instability of marriage have negatively affected fertility rates in East Asia (Fukuda this volume). In addition, the strong focus on the 
Table 1:

Selected characteristics of period and cohort fertility in Southern European and East Asian countries and territories with very low fertility

\begin{tabular}{|c|c|c|c|c|}
\hline & \multicolumn{4}{|c|}{ Southern Europe } \\
\hline & \multicolumn{2}{|c|}{ Greece } & Italy & Spain \\
\hline Period TFR (2019) & \multicolumn{2}{|c|}{$1.34^{1)}$} & 1.29 & 1.23 \\
\hline Tempo-adjusted TFR (2016) & \multicolumn{2}{|c|}{1.49} & 1.47 & 1.43 \\
\hline Completed TFR (cohort 1978) & \multicolumn{2}{|c|}{1.51} & 1.43 & 1.36 \\
\hline Childlessness, cohort $1978(\%)$ & \multicolumn{2}{|c|}{24} & 21 & 25 \\
\hline Women with one child, cohort $1978(\%)$ & \multicolumn{2}{|c|}{-} & - & 28 \\
\hline \multirow[t]{3}{*}{ Mean age at first birth (2018) } & \multicolumn{2}{|c|}{30.4} & 31.2 & 31.0 \\
\hline & \multicolumn{4}{|c|}{ East Asia } \\
\hline & $\begin{array}{l}\text { Hong } \\
\text { Kong }\end{array}$ & Japan & $\begin{array}{l}\text { South } \\
\text { Korea }\end{array}$ & Taiwan \\
\hline Period TFR (2019) & 1.05 & 1.36 & 0.92 & 1.05 \\
\hline Tempo-adjusted TFR (2016) & - & 1.54 & 1.46 & $1.36^{2)}$ \\
\hline Completed TFR (cohort 1978) & $1.25^{3)}$ & 1.47 & 1.53 & $1.58^{4)}$ \\
\hline Childlessness, cohort $1978(\%)$ & $30^{3)}$ & 28 & 18 & $18^{4)}$ \\
\hline Women with one child, cohort $1978(\%)$ & - & 20 & 24 & $23^{4)}$ \\
\hline Mean age at first birth (2018) & - & 30.2 & 31.6 & $30.0^{5)}$ \\
\hline
\end{tabular}

Sources: Human Fertility Database (2020); national statistical offices (for the TFR in 2019); European Demographic Data Sheet (2020) (tempo-adjusted TFR and completed TFR in Southern Europe and Japan); Census and Statistics Department Hong Kong (2020; Tables 6 and 7).

Notes: Data on completed TFR, childlessness and the share of women with one child are based on observed fertility by age 40 and estimated (projected) fertility past that age. 1) Preliminary estimate based on absolute changes in the number of births; 2) data for 2012; 3) data pertain to the 1979 cohort (based on Tables 6 and 7 in Census and Statistics Department Hong Kong (2020)); 4) data pertain to the 1974 cohort; 5) data for 2014.

academic achievements of children has increased the investments of time and money parents are expected to make in their children's education, including in extended extracurricular activities. This "educational arms race" results in lower fertility intentions and reduced fertility (Cheng this volume).

By contrast, in Southern Europe, the initially close link between marriage and childbearing has eroded fast. However, Southern European and East Asian societies share the trend towards a pattern of late independent living and partnership formation among young adults (e.g., Esteve et al. this volume). The late transition to residential independence is fuelled in part by extended education, but even more so by the high and rising costs of housing and the high levels of economic uncertainty among young adults, with many facing unemployment, or employment that is poorly paid or with a non-standard contract. While economic uncertainty has affected young adults and their fertility decisions across all highly developed countries, it 
has had the most "scarring" effects in South-Eastern, Eastern and Southern Europe (Adserà 2011), especially in the wake of the financial crisis of 2007-2012 (Comolli 2017; Matysiak et al. 2020). Southern Europe is also characterised by relatively underdeveloped family policies, with more government resources being spent on the elderly, and a large share of the burden of family care responsibilities being shouldered by kinship and family, and especially by women (Cooke 2009; Pailhé et al. 2019).

\subsection{What factors contribute to the changes in and the diversity of post-transitional fertility?}

Over the past decade, numerous studies have discussed and evaluated the factors and institutional conditions that affect post-transitional fertility levels, fertility trends and their variation, while often proposing new conceptual frameworks. Five broader, partly interrelated factors - i.e., economic uncertainty, gender egalitarianism, changing educational and social stratification in fertility, the impact of migration and institutional support provided to families - feature prominently in these debates. Adverse economic and labour market conditions have been repeatedly shown to have a negative impact on fertility intentions (Fahlén and Oláh 2018; Busetta et al. 2019; Vignoli et al. 2020a) and fertility (Adserà 2011; Sobotka et al. 2011; Comolli 2017). Over time, the conceptualisation of uncertainty has widened beyond the impact of economic shocks. One strand of research has documented the impact of delayed economic independence, more precarious jobs, declining relative income and the general increase in pressures and uncertainties among the younger generations (Mills and Blossfeld 2005; Sanderson et al. 2013). Recently, Vignoli et al. (2020b) extended the concept of uncertainty to incorporate the "imagined futures": i.e., perceptions and narratives of the future that may be disconnected from an individual's current situation.

From a different perspective, Nicolò Cavalli (this volume) argues that demographic behaviour is strongly future-oriented, and that considering the role of "time preferences can add another theoretical micro-foundation to the mechanisms that link individual fertility decisions to institutional factors that operate at the macro level" (p. 257). His main argument, grounded in the concepts of hyperbolic (time) discounting, is built upon two key insights on decision-making: first, that individuals have a preference for earlier rather than later gratification, opting for rewards that are smaller, but occur earlier; and, second, that a conflict between current and future preferences results in people consuming more at present than initially planned (thus "discounting", or penalising, future rewards). Cavalli hypothesises that societies that are more future-oriented are likely to show a lower "bias towards the present", with families tending to invest more in the quality of their children, resulting in lower fertility rates. Empirically, this hypothesis is tested by constructing a Future Orientation Index (FOI) based on worldwide Google queries. The results of this analysis confirm that there is a negative correlation between future orientation and 
the total fertility rate, which flattens out at high levels of future orientation. It would be worth expanding this analysis to fertility timing: i.e., future orientation is likely to lead to more careful planning of births among couples, which may contribute to the fertility postponement observed in many countries.

The structural/economic perspectives on fertility have often neglected the impact of massive changes in women's educational levels and economic achievements over the last half a century. Mills (2010) highlights the complexity of arguments linking different micro- and macro-level perspectives on gender equality and fertility, which focus on issues such as the division of household work and childrearing among couples, but also on institutional factors that lead to unequal opportunities and participation in education, employment and social and political life. Esping-Andersen and Billari (2015) and Goldscheider et al. (2015) link the broader trend towards gender equality both within households and in public institutions to the transformations in fertility patterns in the past decades. The gender revolution framework proposed by Goldscheider et al. (2015) suggests that an initial trend towards institutional gender equality, marked by a rapid rise in higher educational attainment among women and a sharp increase in women's participation in employment, resulted in "less family" and low fertility, as women's labour market activities remained incompatible with their family roles. This incongruence between rising opportunities and aspirations in the public sphere and rigid norms and expectations in the domestic sphere is especially sharp in East Asia today (Cheng this volume). According to Goldscheider et al. (2015), the "second half of the gender revolution", which is driven by the spread of gender egalitarian attitudes and practices within the household, will eventually result in a return to "more family", and, thus, to a rise in fertility and marriage rates. Furthermore, changes in the structure of economic opportunities and improvements in the compatibility of family and career for highly educated women, supported by family policies, could lead to a reversal of the negative association between education and fertility among women. Trude Lappegård (this volume) discusses these arguments with reference to the unexpected recent decline in fertility in the Nordic countries, which are characterised by high levels of both institutional and domestic gender equality. She argues that gender equality must be considered within a wider context of a "changing economy, globalization, and increasing economic uncertainty" (p. 45), and linked to systems of social stratification. Whether gender equality positively affects fertility will depend on the responses of different socio-economic groups (see also Section 3 below).

Across the low-fertility countries, the evidence on the changing social stratification of fertility is mixed. For the Nordic countries, Jalovaara et al. (2019) document that, with the exception of Finland, completed fertility has converged among women across different educational groups born in the late 1960s and early 1970s. In Denmark and Sweden, childlessness has risen sharply among women with low education, reaching much higher levels than among women with medium or high education. Past data for countries in Southern, Central and Eastern Europe, as well as for the United States, Australia and the United Kingdom, show the persistence of a negative education gradient in fertility among women born in the 1960s and 1970s 
(e.g., Berrington et al. 2015; Sobotka et al. 2017; Zang 2019; Gray and Evans 2019). One factor that continues to contribute to lower fertility among highly educated women is their late family formation. Women and men tend to postpone the first birth until after they finish their studies, and educational expansion is the main driver of the trend towards late parenthood across the highly developed countries (Ní Bhrolcháin and Beaujouan 2012).

In the context of continuing education expansion, Michaela Potančoková and Guillaume Marois evaluate the importance of accounting for women in education in their microsimulation projection model for 28 European Union countries (including the United Kingdom): when educational enrolment is included, the projected EUwide TFR is lower than it is in the scenario that accounts for educational attainment, but not enrolment. Their analysis reveals, however, that migration will be the major source of heterogeneity, as it will have strong effects on fertility, the number of births, population size and population distribution across the European Union. The impact of future migration is most clearly illustrated in the high immigration scenario, which assumes that there will be a doubling of the inflow of immigrants from outside of the European Union, roughly corresponding to current levels of immigration to Canada. When contrasted with the scenario in which recent $(2010$ 14) levels of immigration continue, the high immigration scenario would result in a larger female population of reproductive ages, which would, in turn, lead to higher fertility and a steadily increasing number of births, reaching 34.9 million in 2055-59 (vs. 24.8 million in the baseline scenario).

From a different perspective, Alicia Adsera (this volume) argues that return migrants and transnational migrants may contribute to fertility declines in their countries of origin. The flow of financial resources via remittances should ease the pressure on local families to put their children to work, and encourage them to invest in their children's education. At the same time, cheap and accessible communication technologies, including social media, should speed up the transmission of information, and foster new norms about family planning, women's empowerment and smaller family size ideals.

The impact of uncertainty, gender equality, migration and social stratification on fertility is altered by family-related policies and the overall character of the welfare state - which, in turn, affect educational and labour market systems (Neyer 2013). Across the low-fertility countries, governments have been investing more resources in families. However, the evidence on the effects of family policies on fertility is mixed, suggesting that their main impact is on the timing and spacing of births, often fuelling short-term cycles of baby booms and busts (Gauthier 2007; Thévenon and Gauthier 2011; Luci-Greulich and Thévenon 2013). Especially questionable are the effects of family policies designed with explicit pronatalist targets, which are often poorly conceived; have short-term aims; and are usually based on simple indicators affected by changes in the timing of births, especially the period TFR (Sobotka and Lutz 2011; Sobotka et al. 2019). In countries with comprehensive family policies, particular attention has been paid to policies supporting the reconciliation of work and family (OECD 2011), which are most beneficial to highly educated women 
(McDonald and Moyle 2019). Family policies might have neglected some of the needs and preferences of less educated women and men, who often have low-paid and unstable jobs, as well as more complex family trajectories and configurations (see also Lappegård this volume). In most countries, family policies have not yet fully "caught up" with the current diversity of family forms and living arrangements, and there is a need to extend more social protection rights and welfare benefits to children in non-traditional family configurations (Miho and Thévenon 2020).

\section{Demographic debate: what is the most important factor likely to influence future fertility?}

The authors who were invited to contribute to the Demographic Debate section were asked to discuss the following question: "What is the most important factor likely to influence future fertility trends and why?" These contributions were largely drafted before the COVID-19 pandemic started affecting our societies, and they cover a broad range of factors relevant in fertility decisions, either globally, or in selected countries and regions. I have reflected upon some of these answers above. Here, I summarise the key themes and ideas.

At a general level, the contributions by Wolfgang Lutz and Anna Rotkirch argue that the changes that happen in our minds - i.e., changes in reproductive ideals, plans, desires and preferences - will be the key drivers of future fertility. Rotkirch highlights that the "wish to have a child" is the main determinant of fertility behaviour. Fertility preferences may change as a result of economic and existential uncertainty, and of lifestyle changes (see Section 4 below).

In the context of relatively high fertility in Sub-Saharan Africa, the essays by Alicia Adsera and Wolfgang Lutz stress the paramount role of education both in driving the shift towards smaller family size ideals, and in empowering women. This process of empowerment includes ensuring that women have better knowledge of and access to contraception and reproductive health services, but also that women are able to persuade their partners and extended family to allow them to pursue their family size desires (Lutz this volume). The necessity of empowering women to overcome the barriers and obstacles to realising their own fertility desires is also emphasised by Stuart Gietel-Basten. What are the conditions needed for educational expansion and for achieving a smaller ideal family size in the region? Alicia Adsera highlights the importance of governance and political stability, with wars and conflicts leading to displacement, less access to education, earlier marriage and higher fertility. She discusses the impact of resources in the form of remittances, and of the new values disseminated by migrants living in more affluent countries with lower fertility.

In low-fertility societies, Albert Esteve, Diederik Boertien, Ryohei Mogi and Mariona Lozano argue that the intensity and timing of partnership formation are the most important factors in the variation in contemporary fertility, and that other social and economic factors primarily affect fertility by influencing the number of 
people who live independently and have a stable partnership. The importance of union formation, and specifically of marriage, is also discussed by Setsuya Fukuda. In the context of Japan and other East Asian countries, marriage is perceived as a precondition for childbearing, as reproduction occurs almost exclusively within marriage. At the same time, the share of the population who are unmarried or nonpartnered has risen, with a majority of single men and women aged 18-34 reporting that they are not in a dating relationship. Moreover, marriages have become less stable, and the "prevalence of divorce and its consequences for remarriage and fertility have become critical factors to consider" when evaluating the potential impact of marriage on future fertility (p. 75).

The role of gender egalitarian values and behaviour is highlighted in the contributions by Trude Lappegård and Stuart Gietel-Basten. Gietel-Basten argues that if the next generation manages to "draw up a new reproductive contract based on equity (...) the biggest hurdle to the actualisation of reproductive preferences will be removed, and this shift could, in turn, have a dramatic impact on fertility rates in the future" (p. 41).

The joint forces of economic uncertainty, rising social status disparities and the shift towards more egalitarian gender relations are likely to lead to a reversal of education and social status stratification in marriage and fertility rates. Setsuya Fukuda suggests that education will become one of the key factors influencing marriage in East Asia, as future marriage trends will be driven by rising labour market uncertainty and non-standard employment, which could erode marriage opportunities, especially for the less educated; and by more equal sharing of gender roles, which could facilitate marriage among better educated women. In a similar vein, Trude Lappegård expects that the eroding economic position of the lower educated and the rising preference for a partner with high earning potential and egalitarian attitudes will mean that "finding a partner and establishing a longterm relationship is likely to be especially difficult for both men and women with low education" (p. 46). As a result, individuals with low education and poor job prospects will increasingly postpone parenthood, and will thus have fewer children. Wolfgang Lutz anticipates that people with intermediate levels of education and income in particular will struggle to combine work and family, and to make ends meet. By contrast, high educational attainment is strongly associated with characteristics that will empower women and couples, giving them skills and resources to better combine career, leisure and family, and "to come closer to their ideal of having two children than women with intermediate income levels" - which could, in turn, lead to a U-shaped gradient in fertility by education (p. 68).

What are the main policies that could support future fertility? Discussions of policies occupy surprisingly little space in the contributions in this volume. Alicia Adsera highlights the importance of migration policies, which will determine the size and the composition of migrant flows into the more developed countries, and will, in turn, affect the integration of migrants, and their subsequent fertility and marriage behaviour (see also Potančoková and Marois). Albert Esteve and colleagues emphasise the impact of policies that support young adults in living independently and forming a stable partnership, including policies that improve 
labour market opportunities and access to childcare and housing. Setsuya Fukuda stresses the importance of policies supporting female employment and work-family balance in East Asia. In a broader perspective, Stuart Gietel-Basten suggests putting gender equity at the heart of the reproductive contract for the $21^{\text {st }}$ century (p. 41).

\section{Looking into an uncertain future}

The past decade has seen unexpected fertility shifts and reversals in many regions. In particular, the contributions commenting on the Nordic countries highlight the surprising and at times dramatic fertility declines that continued during the economic recovery after 2012, and that challenge the established explanations of fertility change and variation (contributions by Adsera, Lutz and Rotkirch). Arguably more consequential is the return and the persistence of "lowest-low" fertility in Southern Europe and East Asia, where fertility rates have not recovered in the aftermath of the Great Recession, and where the continuing postponement of parenthood leaves women and couples with an ever-narrower window for a fertility recovery in the future.

Are we experiencing yet another temporary shift in fertility, similar to past swings in fertility rates in countries such as Denmark and Sweden? Or are we entering a new era of lower reproductive aspirations and depressed fertility? The jury is still out, but there are many signs that the reproductive landscape is being redrawn and the contours of the new one are only slowly emerging. One of the few certainties is that sustaining replacement-level fertility is not on the menu of choices and options in this new landscape.

The media, especially in the United States, has reported numerous shifts in the lives of the younger generations growing up in the era of social media (Twenge 2017). It has, for example, been observed that compared to older generations, today's young people tend to have fewer and later sexual and dating relationships (The sex recession; Julian 2018); and they are less likely to engage in risky behaviours, such as smoking and excessive alcohol and drug consumption. However, young people are also more anxious and sleep-deprived (Have smartphones destroyed a generation?; Twenge 2017); and, crucially, they face a crisis of reproduction (The end of babies; Sussman 2019). In her insightful contribution, Anna Rotkirch, draws from qualitative and quantitative research in Finland to provide a compelling outline of the new landscape of reproduction marked by new pressures and uncertainties, less certain reproductive preferences and a less positive image of parenthood. "Traditional" explanations based on economic and policy factors are not sufficient to explain recent fertility declines, as the lives of young Finns "have not grown objectively worse (...) family policies and leave benefits remain generous, and levels of gender equality have increased" (p. 54). New uncertainties and worries about the future (see also Vignoli et al. 2020b) are partly fuelled by social media and concerns about issues like climate change. Moreover, young adults are increasingly reluctant to give up the joys of their 
childfree lifestyle: as Rotkirch argues, "having a child can be seen as a sacrifice, while remaining childless is associated with having access to the positive aspects of life (sleep, sex, career)" (p. 57).

The ongoing coronavirus pandemic is likely to add yet another layer of insecurity, and will accelerate the trend towards putting off parenthood (Lindberg et al. 2020; Aassve et al. 2020). In Southern Europe and parts of South-Eastern and Eastern Europe, the disruption caused by the pandemic will further deepen the existing economic and labour market challenges faced by young adults in countries with high unemployment, unstable jobs and limited family policies. The lingering effects of the Great Recession and the unfolding effects of the COVID-19 pandemic are likely to combine into a perfect storm that will disrupt the lives of younger generations, and will bring about a fertility shock. In East Asia and elsewhere, the pandemic may strengthen the trend towards having fewer social contacts, less in-person interaction, fewer partnerships and fewer and later marriages (Settersten et al. 2020). Even if the effects of the COVID-19 pandemic prove to be mostly temporary, many countries are likely to experience unprecedented drops in fertility rates, with some seeing their total fertility rate falling below the threshold of one. Our established terminology for "lowest-low" or "ultra-low" fertility might become insufficient to describe these new fertility lows.

It is unclear whether the effects of the pandemic are likely to persist over the longer term, fundamentally reshaping our social relationships and family life (Settersten et al. 2020). Likewise, it is not yet known whether the pressures in the lives of the younger generation and their generally more sceptical attitudes towards parenthood - illustrated in the examples from Finland and the United States - can be generalised to all low-fertility countries. Stuart Gietel-Basten paints another possible future in which Millennials and Generation $\mathrm{Z}$ reshape the economic and social system in more equitable and fairer ways that could make societies more friendly to families and children. However the future turns out, research on fertility across time and space, and on the forces affecting fertility change and variation, is likely to remain relevant, exciting and surprising in the decades to come.

\section{Acknowledgements}

This article has greatly benefited from the comments and suggestions of the guest editors of this volume, Aiva Jasilioniene, Diego Ramiro Fariñas and Kryštof Zeman; and of the managing editor, Maria Winkler-Dworak.

\section{References}

Aassve, A., N. Cavalli, L. Mencarini, S. Plach and M. L. Bacci 2020. The COVID-19 pandemic and human fertility. Science 369(6502): 370-371. https://doi.org/10.1126/ science.abc9520. 
Adserà, A. 2011. Where are the babies? Labour market conditions and fertility in Europe. European Journal of Population 27(1): 1-32. https://doi.org/10.1007/s10680-010-9222-x.

Al Zalak, Z. and A. Goujon 2017. Exploring the fertility trend in Egypt. Demographic Research 37(Article 32): 995-1030. https://doi.org/10.4054/DemRes.2017.37.32.

Basten, S. and B. Gu 2013. National and regional trends in ideal family size in China. Paper presented at the IUSSP International Population Conference, Busan, Korea, 26-31 August 2013. Accessed in November 2013 at http://www.iussp.org/sites/default/files/ event_call_for_papers/GU\%20and\%20Basten\%20Long\%20Abstract.pdf.

Beaujouan, É. and C. Berghammer 2019. The gap between lifetime fertility intentions and completed fertility in Europe and the United States: A cohort approach. Population Research and Policy Review 38(4): 507-535. https://doi.org/10.1007/s11113-019-095163.

Beaujouan, É., A. Reimondos, E. Gray, A. Evans and T. Sobotka 2019. Declining realisation of reproductive intentions with age. Human Reproduction 34(10): 1906-1914. https: //doi.org/10.1093/humrep/dez150.

Berrington, A and S. Pattaro 2014. Educational differences in fertility desires, intentions and behaviour: A life course perspective. Advances in Life Course Research 21(September 2014): 10-27. https://doi.org/10.1016/j.alcr.2013.12.003.

Berrington, A., J. Stone and É. Beaujouan 2015. Educational differences in timing and quantum of childbearing in Britain: A study of cohorts born 1940-1969. Demographic Research 33(Article 26): 733-764. https://doi.org/10.4054/DemRes.2015.33.26.

Bongaarts, J. 2003. Completing the fertility transition in the developing world: The role of educational differences and fertility preferences. Population Studies 57(3): 321-335. https://doi.org/10.1080/0032472032000137835.

Bongaarts, J. 2006. The causes of stalling fertility transitions. Studies in Family Planning 37(1): 1-16. https://doi.org/10.1111/j.1728-4465.2006.00079.x.

Bongaarts, J. 2017. Africa's unique fertility transition. Population and Development Review 43(Supplement): 39-58. https://doi.org/10.1111/j.1728-4457.2016.00164.x.

Bongaarts, J. and J. Casterline. 2013. Fertility transition: Is sub-Saharan Africa different? Population and Development Review 38(Suppl. 1): 153-168. https://doi.org/10.1111/j. 1728-4457.2013.00557.x.

Bongaarts, J., B. S. Mensch and A. K. Blanc 2017. Trends in the age at reproductive transitions in the developing world: The role of education. Population Studies 71(2): 139-154. https://doi.org/10.1080/00324728.2017.1291986.

Brinton, M. C. and E. Oh 2019. Babies, work, or both? Highly educated women's employment and fertility in East Asia. American Journal of Sociology 125(1): 105-140. https://doi.org/ 10.1086/704369.

Bryant, J. 2007. Theories of fertility decline and the evidence from development indicators. Population and Development Review 33(1): 101-127. https://doi.org/10.1111/j.1728-4457. 2007.00160.x.

Busetta, A., D. Mendola and D. Vignoli 2019. Persistent joblessness and fertility intentions. Demographic Research 40(Article 8): 185-218. https://doi.org/10.4054/DemRes.2019. 40.8 . 
Census and Statistics Department Hong Kong 2020. Hong Kong population projections 2020-2069. Kowloon, Hong Kong: Demographic Statistics Section, Census and Statistics Department.

Coleman, D. A. 1998. Reproduction and survival in an unknown world. NIDI Hofstee Lecture Series 5, NIDI, The Hague.

Comolli, C. L. 2017. The fertility response to the Great Recession in Europe and the United States: Structural economic conditions and perceived economic uncertainty. Demographic Research 36(51): 1549-1600. https://doi.org/10.4054/DemRes.2017.36.51.

Cooke, L. P. 2009. Gender equity and fertility in Italy and Spain. Journal of Social Policy 38(1): 123-140. https://doi.org/10.1017/S0047279408002584.

Edmonston, B., S. M. Lee and Z. Wu 2010. Fertility Intentions in Canada: Change or no change? Canadian Studies in Population 37(3-4): 297-337. https://doi.org/10.25336/ P6B037.

Esping-Andersen, G. and F. C. Billari 2015. Re-theorizing family demographics. Population and Development Review 41(1): 1-31. https://doi.org/10.1111/j.1728-4457.2015.00024.x.

Fahlén, S. and L. S. Oláh 2018. Economic uncertainty and first-birth intentions in Europe. Demographic Research 39(Article 28): 795-834. https://doi.org/10.4054/DemRes.2018. 39.28.

Fukuda, N. and T. T. Saotome 2018. Fertility preferences in Japan. In Family demography in Asia. A comparative analysis of fertility preferences, eds S. Gietel-Basten, J. Casterline, and M. K. Choe, 171-184. Edward Elgar Publishing.

Funabashi, Y. 2018. Japan's population implosion. The 50 million shock. Singapore, Palgrave Macmillan.

Gauthier, A. H. 2007. The impact of family policies on fertility in industrialized countries: A review of the literature. Population Research and Policy Review 26: 232-346. https://doi.org/10.1007/s11113-007-9033-X.

Goldscheider, F., E. Bernhardt and T. Lappegård 2015. The gender revolution: A framework for understanding changing family and demographic behavior. Population and Development Review 41(2): 207-239. https://doi.org/10.1111/j.1728-4457.2015.00045.x.

Golini, A. 1998. How low can fertility be? An empirical exploration. Population and Development Review 24(1): 59-73. https://doi.org/10.2307/2808122.

Goujon, A., W. Lutz and S. KC 2015. Education stalls and subsequent stalls in African fertility: A descriptive overview. Demographic Research 33(Article 47): 1281-1296. https://doi.org/10.4054/DemRes.2015.33.47.

Gray, E. and A. Evans 2019. Changing education, changing fertility: a decomposition of completed fertility in Australia. Australian Population Studies 3(2): 1-15. https://doi.org/ 10.37970/aps.v3i2.42.

Hellstrand, J., J. Nisén and M. Myrskylä 2020a. All-time low period fertility in Finland: Demographic drivers, tempo effects, and cohort implications. Population Studies 74(3): 315-329. https://doi.org/10.1080/00324728.2020.1750677.

Hellstrand, J., J. Nisén, V. Miranda, P. Fallesen, L. Dommermuth and M. Myrskylä 2020b. Not just later, but fewer: novel trends in cohort fertility in the Nordic countries. MPIDR Working Papers No. 2020-007, Max Planck Institute for Demographic Research, Rostock, Germany. https://doi.org/10.4054/MPIDR-WP-2020-007. 
Human Fertility Database 2020. Data on period TFR, tempo-adjusted TFR, parity distribution and cumulated cohort fertility rates by age and birth order. Max Planck Institute for Demographic Research (Germany) and Vienna Institute of Demography (Austria). www.humanfertility.org, accessed October 2020.

Ishihara, O., S. C. Jwa, A. Kuwahara, Y. Katagiri, Y. Kuwabara, T. Hamatani, M. Harada and T. Ichikawa 2020. Assisted reproductive technology in Japan: A summary report for 2017 by the Ethics Committee of the Japan Society of Obstetrics and Gynecology. Reproductive Medicine and Biology 19(1): 3-12. https://doi.org/10.1002/rmb2.12307.

Jalovaara, M., G. Neyer, G. Andersson, J. Dahlberg, L. Dommermuth, P. Fallesen and T. Lappegård 2019. Education, gender, and cohort fertility in the Nordic countries. European Journal of Population 35(3): 563-586. https://doi.org/10.1007/s10680-018-9492-2.

Julian, K. 2018. Why are young people having so little sex? The Atlantic, December 2018. https://www.theatlantic.com/magazine/archive/2018/12/the-sex-recession/573949/.

Kebede, E., A. Goujon and W. Lutz 2019. Stalls in Africa's fertility decline partly result from disruptions in female education. PNAS 116(8): 2891-2896. https://doi.org/10.1073/pnas. 1717288116.

KOSIS 2020. Total fertility rates and age-specific fertility rates for provinces. 2019 (Table DT_1B81A21). Statistics Korea, accessed 20 October 2020 at http://kosis.kr/statHtml/ statHtml.do?orgId=101\&tblId=DT_1B81A21\&language=en\&conn_path=I3.

Leridon, H. 2008. A new estimate of permanent sterility by age: Sterility defined as the inability to conceive. Population Studies 62(1): 15-24. https://doi.org/10.1080/ 00324720701804207.

Lindberg, L. D., A. VandeVusse, J. Mueller and M. Kirstein 2020. Early impacts of the COVID-19 pandemic: Findings from the 2020 Guttmacher survey of reproductive health experiences. New York: Guttmacher Institute, 24 June 2020. https://www.guttmacher.org/report/early-impacts-covid-19-pandemic-findings-2020guttmacher-survey-reproductive-health.

Luci-Greulich, A. and O. Thévenon 2013. The impact of family policies on fertility trends in developed countries. European Journal of Population 29(4): 387-416. https://doi.org/10. 1007/s10680-013-9295-4.

Lutz, W., V. Skirbekk and M. R. Testa 2006. The low fertility trap hypothesis. Forces that may lead to further postponement and fewer births in Europe. Vienna Yearbook of Population Research 2006: 167-192. https://doi.org/10.1553/populationyearbook2006s167.

Lutz, W., A. Goujon, S. KC, M. Stonawski and N. Stilianakis 2018. Demographic and human capital scenarios for the 21 st Century: 2018 assessment for 201 countries. Luxembourg: Publications Office of the European Union. https://ec.europa.eu/jrc/sites/jrcsh/files/lutz et_al_2018_demographic_and_human_capital.pdf.

Matysiak, A., T. Sobotka and D. Vignoli 2020. The great recession and fertility in Europe: A sub-national analysis. European Journal of Population. https://doi.org/10.1007/s10680020-09556-y.

McDonald, P. and H. Moyle 2019. In Australia fertility is falling only for low educated women. N-IUSSP, 1 July 2019. https://www.niussp.org/article/in-australiafertility-is-falling-only-for-low-educated-womenen-australie-la-fecondite-baisseuniquement-chez-les-femmes-peu-scolarisees/. 
Miho, A. and O. Thévenon 2020. Treating all children equally? Why policies should adapt to evolving family living arrangements. OECD Social, Employment and Migration Working Papers, No. 240, OECD Publishing, Paris. https://doi.org/10.1787/83307d97-en.

Mills, M. 2010. Gender roles, gender (in)equality and fertility: An empirical test of five gender equity indices. Canadian Studies in Population 37(3-4): 445-474. https://doi.org/ 10.25336/P6131Q.

Mills, M. and H.-P. Blossfeld 2005. Globalization, uncertainty and the early life course. A theoretical framework. In Globalization, uncertainty and youth in society, eds H.P. Blossfeld, E. Klijzing, M. Mills and K. Kurz, 1-24. London/New York: Routledge Advances in Sociology Series.

Myrskylä, M., H.-P. Kohler and F. C. Billari 2009. Advances in development reverse fertility declines. Nature 460(6 August 2009): 741-743. https://doi.org/10.1038/nature08230.

Neyer, G. 2013. Welfare states, family policies, and fertility in Europe. In The demography of Europe, eds G. Neyer, G. Andersson, H. Kulu, L. Bernardi and C. Bühler, 29-53. Dordrecht: Springer. https://doi.org/10.1007/978-90-481-8978-6_3.

Ní Bhrolcháin, M. and É. Beaujouan 2012. Fertility postponement is largely due to rising educational enrolment. Population Studies 66(3): 311-327. https://doi.org/10.1080/ 00324728.2012 .697569$.

OECD 2011. Doing better for families. Paris: OECD Publishing. https://doi.org/10.1787/ 9789264098732-en.

Pailhé, A., A. Solaz and M. L. Tanturri 2019. The time cost of raising children in different fertility contexts: evidence from France and Italy. European Journal of Population 35: 223-261. https://doi.org/10.1007/s10680-018-9470-8.

Potts, M., V. Gidi, M. Campbell and S. Zureick 2011. Niger: too little, too late. International Perspectives on Sexual and Reproductive Health 37(2): 95-101. https://doi.org/10.1363/ 3709511.

Raymo, J. M., H. Park, Y. Xie and W. J. J. Yeung 2015. Marriage and family in East Asia: Continuity and change. Annual Review of Sociology 41(2015): 471-492. https://doi.org/10.1146/annurev-soc-073014-11242.

Registro, S. E. F. 2018. Registro Nacional de Actividad 2018-Registro SEF. Informe estadístico de Técnicas de Reproducción Asistida 2018. Sociedad Española de Fertilidad. https://www.registrosef.com/public/docs/sef2018_IAFIVm.pdf

Rybińska, A. 2020. Trends in intentions to remain childless in the United States. Population Research and Policy Review. https://doi.org/10.1007/s11113-020-09604-9.

Sanderson, W. C., V. Skirbekk and M. Stonawski 2013. Young adult failure to thrive syndrome. Finnish Yearbook of Population Research 48(2013): 169-187. https://doi.org/10.23979/ fypr.40934.

Settersten, R. A., L. Bernardi, J. Härkönen, T. C. Antonucci, P. A. Dykstra, J. Heckhausen, D. Kuh, K. U. Mayer, P. Moen, J. T. Mortimer, C. H. Mulder, T. M. Smeeding, T. van der Lippe, G. O. Hagestad, M. Kohli, R. Levy, I. Schoon and E. Thomson 2020. Understanding the effects of Covid-19 through a life course lens. Advances in Life Course Research 45. https://doi.org/10.1016/j.alcr.2020.100360.

Shapiro, D. and T. Gebreselassie 2008. Fertility transition in sub-Saharan Africa: Falling and stalling. African Population Studies 23(1): 3-23. https://doi.org/10.11564/23-1-310. 
Shapiro, D. and A. Hinde 2017. On the pace of fertility decline in sub-Saharan Africa. Demographic Research 37(Article 40): 1327-1338. https://doi.org/10.4054/DemRes.2017. 37.40 .

Sobotka, T. 2017. Post-transitional fertility: the role of childbearing postponement in fuelling the shift to low and unstable fertility levels. Journal of Biosocial Science 49(S1): S20-S45. https://doi.org/10.1017/S0021932017000323.

Sobotka, T. and É. Beaujouan 2014. Two is best? The persistence of a two-child family ideal in Europe. Population and Development Review 40(3): 391-419. https://doi.org/10.1111/j. 1728-4457.2014.00691.x.

Sobotka, T. and É. Beaujouan 2018. Late motherhood in low-fertility countries: Reproductive intentions, trends and consequences. In Preventing age related fertility loss, ed D. Stoop, 11-29. Springer, Cham. https://doi.org/10.1007/978-3-319-14857-1_2.

Sobotka, T., É. Beaujouan and J. Van Bavel 2017. Introduction: Education and fertility in low-fertility settings. Vienna Yearbook of Population Research 15(2017): 1-16. https://doi.org/10.1553/populationyearbook2017s001.

Sobotka, T. and W. Lutz 2011. Misleading policy messages derived from the period TFR: should we stop using it? Comparative Population Studies - Zeitschrift für Bevölkerungswissenschaft 35(3) (2010): 637-664. https://doi.org/10.4232/10.CPoS2010-1.

Sobotka, T., A. Matysiak and Z. Brzozowska 2019. Policy responses to low fertility: how effective are they? New York: UNFPA, Working Paper No. 1, May 2019 Technical Division Working Paper Series, Population and Development Branch. https://www.unfpa. org/publications/policy-responses-low-fertility-how-effective-are-they.

Sobotka, T., V. Skirbekk and D. Philipov 2011. Economic recession and fertility in the developed world. Population and Development Review 37(2): 267-306. https://doi.org/10. 1111/j.1728-4457.2011.00411.x.

Spoorenberg, T. 2015. Explaining recent fertility increase in Central Asia. Asian Population Studies 11(2): 115-133. https://doi.org/10.1080/17441730.2015.102727.

Strulik, H. and S. Vollmer 2013. The fertility transition around the world. Journal of Population Economics 28(1): 31-44. https://doi.org/10.1007/s00148-013-0496-2.

Sussman, A. L. 2019. The end of babies. The New York Times, 16 November 2019. https://www.nytimes.com/interactive/2019/11/16/opinion/sunday/capitalism-children. html

Thévenon, O. and A. H. Gauthier 2011. Family policies in developed countries: A fertilitybooster' with side-effects. Community, Work E Family 14(2): 197-216. https://doi.org/10. 1080/13668803.2011.571400.

Twenge, J. 2017. Have smartphones destroyed a generation? The Atlantic, September 2017. https://www.theatlantic.com/magazine/archive/2017/09/has-the-smartphone-destroyeda-generation/534198/.

UN 2019. World population prospects 2019. New York: United Nations, Department of Economic and Social Affairs Population Dynamics. https://population.un.org/wpp/.

VID 2020. European demographic datasheet 2020. Vienna Institute of Demography (VID), Austrian Academy of Sciences (ÖAW) and International Institute for Applied Systems Analysis (IIASA); Wittgenstein Centre for Demography and Global Human Capital. Available at www.populationeurope.org. 
Vignoli, D., L. Mencarini and G. Alderotti 2020a. Is the effect of job uncertainty on fertility intentions channeled by subjective well-being? Advances in Life Course Research 46. https://doi.org/10.1016/j.alcr.2020.100343.

Vignoli, D., R. Guetto, G. Bazzani, E. Pirani and A. Minello 2020b. A reflection on economic uncertainty and fertility in Europe: The Narrative Framework. Genus 76(1): 1-27. https://doi.org/10.1186/s41118-020-00094-3.

Vollset, S. E., E. Goren, et al. 2020. Fertility, mortality, migration, and population scenarios for 195 countries and territories from 2017 to 2100: A forecasting analysis for the Global Burden of Disease Study. The Lancet 396(10258): 1285-1306. https://doi.org/10.1016/ S0140-6736(20)30677-2.

Zang, E. 2019. Women's educational attainment and fertility among Generation X in the United States. Population Studies 73(3): 335-351. https://doi.org/10.1080/00324728.2019. 1658799.

Zeman, K., É. Beaujouan, Z. Brzozowska and T. Sobotka 2018. Cohort fertility decline in low fertility countries: Decomposition using parity progression ratios. Demographic Research 38(25): 651-690. https://doi.org/10.4054/DemRes.2018.38.25.

Open Access This article is published under the terms of the Creative Commons Attribution 4.0 International License (https://creativecommons.org/licenses/by/4.0/) that allows the sharing, use and adaptation in any medium, provided that the user gives appropriate credit, provides a link to the license, and indicates if changes were made. 